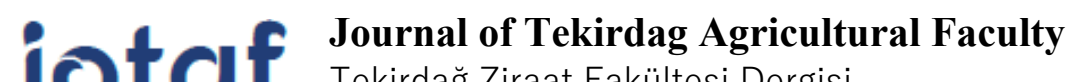 \\ Tekirdağ Ziraat Fakültesi Dergisi
}

\section{Türkiye'de Pamuk Üretimi İle Fiyatı Arasındaki İlişkinin Koyck Yaklaşımı İle Analizi}

Analysis of the Relationship Between Cotton Production and Prices by using Koyck Approach in Turkey

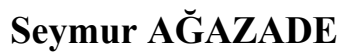

\section{$\ddot{O} z$}

Bu çalışmada, Türkiye için pamuk üretim miktarı ile pamuk reel fiyatları arasındaki ilişkinin gecikmesi dağıtılmış modellerden olan Koyck yaklaşımı çerçevesinde incelenmesi amaçlanmıştır. Bu amaç doğrultusunda, Türkiye'de pamuk yetiştirilen 19 ile ait veri seti ve panel veri yöntemleri kullanılmıştır. Pamuk reel fiyatları, her ile ait nominal pamuk fiyatları ile Türkiye geneline ait tüketici fiyatları endeksi kullanılarak hesaplanmıştır. Çalışmada panel veri yatay kesit bağımlılığına yönelik yapılan incelemede farklı illere ait hem pamuk üretim miktarı hem de pamuk reel fiyat serileri arasında pozitif korelasyon olduğu görülmüştür. Bu korelasyonun pamuk üretim miktarı için \%21.6 ve reel pamuk fiyatları için \%90.4 oranında olduğu görülmüştür. Panel birim kök testine ait bulgular, pamuk üretim miktarı ve pamuk reel fiyatı serilerinin durağan olduğunu desteklemiştir. Bu sonuç hem pamuk üretim miktarı hem de reel pamuk fiyatı serisinin meydana gelen dış şoklardan sonra kendi uzun dönem düzeylerine dönme eğilimi gösterdiğine işaret etmektedir. Panel veri sabit etkiler modelinin temel varsayımlarına ilişkin tespit edilen sorunlar dikkate alınarak, pamuk üretim fonksiyonu dirençli standart hatalara dayanan ve otokorelasyon, değişen varyans ve yatay kesit bağımlılığının varlığında da etkin sonuçlar sağlayan bir yaklaşım çerçevesinde tahmin edilmiştir. Koyck yaklaşımı çerçevesinde yapılan panel veri sabit etkili model tahmin sonuçları ise reel pamuk fiyatında meydana gelen \%1'lik bir değişmenin pamuk üretim miktarını aynı yıl \%0.31 oranında ve aynı yönde etkilediğini göstermiş̧ir. Reel pamuk fiyatındaki bu değişim 1 ve 2 yıl sonraki pamuk üretim miktarını sırasıyla $\% 0.26$ ve $\% 0.22$ oranında etkilemektedir. Çalışmada, pamuk reel fiyatında meydana gelen değişmenin pamuk üretim miktarına yansıması için gereken ortalama süre ise 4.99 yıl olarak hesaplanmıştır.

Anahtar Kelimeler: Pamuk üretim miktarı, Reel pamuk fiyatı, Koyck yaklaşımı, Panel veri, Türkiye

\footnotetext{
1*Sorumlu Yazar/Corresponding Author: Seymur AGAZADE, Alanya Alaaddin Keykubat Üniversitesi, Turizm Fakültesi, Alanya / Antalya, Türkiye. E-mail: seymur.agazade@alanya.edu.tr (iD OrcID: 0000-0001-5484-5189 Atıf/Citation: AGAZADE , S. Türkiye'de Pamuk Üretimi İle Fiyatı Arasındaki Illişkinin Koyck Yaklaşımı İle Analizi. Tekirdă̆ Ziraat Fakültesi Dergisi, 18 (3), $386-399$. (CBu çalışma Tekirdağ Namık Kemal Üniversitesi tarafından Creative Commons Lisansı (https://creativecommons.org/licenses/by-nc/4.0/) kapsamında yayınlanmıştır. Tekirdağ 2021
} 


\begin{abstract}
In this study, the relationship between the amount of cotton production and real cotton prices was investigated for Turkey in the framework of Koyck approach, one of the distributed lag models. For this purpose, data for the 19 cotton grown provinces of Turkey and panel data methods were used. Cotton real prices were calculated using the nominal cotton prices of each province and the consumer price index of Turkey in general. Panel data crosssectional dependency analyses show that there are positive correlations between both the amount of cotton production and real price series of different provinces. This correlation was found to be $21.6 \%$ for cotton production and $90.4 \%$ for real cotton prices. Findings of panel unit root tests supported that cotton production and cotton real price series were stationary. This result supports that both series return to their long run levels after external shocks. Taking into account the problems related to the basic assumptions of the fixed effects model, the cotton production function was estimated in the context of an approach, which is based on robust standard errors and provides efficient results in the presence of autocorrelation, heteroscedasticity and cross-sectional dependence. The findings of the panel data fixed effect model estimated within the framework of the Koyck approach showed that a $1 \%$ change in the real cotton price affected cotton production in the same direction by $0.31 \%$ in the same year. Furthermore, this change in real cotton price affects cotton production by $0.26 \%$ and $0.22 \%$ after 1 and 2 years, respectively. Finally, the average time required to reflect the real cotton price changes on the production was calculated as 4.99 years.
\end{abstract}

Keywords: Cotton production amount, Real cotton price, Koyck approach, Panel data, Turkey 


\section{Giriş}

Türkiye dünya pamuk üretiminin ülkeler sıralamasında üst sıralarda yer alan ülkelerden biridir. Buna göre 2018/2019 döneminde Hindistan, ABD, Çin, Brezilya ve Pakistan'dan sonra Türkiye altıncı sırada gelmektedir. Bu çalışmada, önemli miktarda pamuk üretiminin yapıldığı Türkiye için pamuk üretim miktarı üzerinde pamuk fiyatlarının etkisi araştırılmıştır. Bilindiği gibi, tarım ürünlerinin üretimi cari dönemdeki fiyatların yanı sıra önceki dönemlere ait fiyatlara da önemli derecede duyarlı olabilmektedir. Buna ilişkin olarak, iktisat teorisinde örümcek ağı teoremi olarak bilinen yaklaşım da, özellikle tarım ürünlerinde üretime ilişkin verilen kararlarda önceki döneme ait fiyat düzeyinin dikkate alınması ile üretim miktarının ve fiyatların sergileyebileceği dalgalanmaları açıklamaya çalışmaktadır. Tarım ürünlerinin bu özelliğine bağlı olarak, gecikmesi dağıtılmış modeller üretim miktarı ve fiyat ilişkisinin incelenmesinde önemli kolaylıklar sağlamaktadır. Bu nedenle, gecikmesi dağıtılmış modeller tarım ürünlerine ilişkin tahminlerde yaygın bir şekilde kullanılmaktadır. Bu çalışmada uygulanan Koyck (1954) yaklaşımı da, ilgili literatürde en yaygın şekilde kullanılan gecikmesi dağıtılmış modeller arasında yer almaktadır.

Türkiye için pamuk fiyatlarının pamuk üretimi üzerindeki etkisi sınırlı sayıda çalışmada incelenmiştir. Pamuk üretiminin fonksiyonel analizine yönelik kısıtlı sayıdaki çalışmanın da ağırlıklı olarak ürün maliyeti ve üretim tekniklerinin incelenmesi konularına yoğunlaştığı görülmektedir (Semerci ve Çelik, 2018). Pamuk fiyatlarının pamuk üretim miktarı üzerindeki etkisinin incelendiği çalışmalara Yurdakul (1998), Aktaş (2006), Özer ve ark. (2014) Karaman ve ark. (2015), Özüdoğru ve Miran (2015), Önder (2017) ve Eski ve Kayalak (2018) gibi çalışmalar örnek verilebilir. Dünya pamuk sektörünün temel sorununu, fiyatlarda ortaya çıkan dalgalanmalar ve düşüş eğilimleri şeklinde ifade eden Özer ve İlkdoğan (2013) ise, pamuk fiyatlarındaki istikrarsızlığın etkilerinin azaltılabilmesi için gelecekte oluşacak pamuk fiyatının önemini vurgulamış ve buna yönelik tahminler yapmışlar. Belirtilen araştırmalardan birinde Önder (2017), Türkiye'nin dört üretim bölgesine ait panel veri kullanmıştır. Diğer çalışmalarda yapılan analizlerde ise, zaman serisi yöntemleri kullanılmış olup yapılan analizler genellikle sınırlı gözleme dayanmaktadır. Belirtilen çalışmalardan Eski ve Kayalak (2018) hariç diğerlerinde pamuk nominal fiyatları dikkate alınmıştır. Bu çalışmada ise, pamuk üretim miktarı ile reel fiyatı arasındaki ilişki çok daha kapsamlı bir veri seti kullanılarak incelenmiştir. Yurdakul (1998), Koyck (1954) modelini kullanmıştır. Fakat gözlem sayısı oldukça kısıtlıdır. Koyck (1954) modelinin tarım ürünlerine ilişkin tahminlerde yaygın şekilde kullanıldığı Dikmen (2006), Erdal (2006), Özçelik ve Özer (2006), Erdal ve Erdal (2008), Çetinkaya (2012), Doğan ve ark. (2014), Çelik (2014 ve 2015), Özbay ve Çelik (2016), Akgül ve Yıldız (2016), Arısoy ve Bayramoğlu (2017) ve Berk (2017) gibi çalışmalardan da anlaşılmaktadır. Bu çalışmalarda farklı tarım ürünlerinin fiyatlarının üretim miktarları üzerindeki etkisi belirtilen model çerçevesinde tahmin edilmiştir.

Gecikmesi dağıtılmış modeller iktisadi değişkenleri kapsayan çalışmalarda yaygın bir şekilde kullanılmakta olup kurumsal, psikolojik, yapısal olmak üzere birçok nedenden dolayı ortaya çıkabilecek olan değişkenlerin gecikmeli etkilerinin de modellenmesine imkân tanımaktadır. Fakat bu modellerde bağımsız değişkene ait gecikmeli değerlerin açıklayıcı değişken olarak yer alması çoklu bağlantı sorununa neden olabilmektedir. Ayrıca gecikmesi dağıtılmış modellerin kullanımı ile yapılan tahminler önemli gözlem kaybına da yol açabilmektedir. Koyck (1954) yaklaşımı ise, bu sorunlara neden olmadan ilgili modelin tahmin edilmesine olanak sağlamaktadır. Pamuk reel fiyatlarının kullanılmasının yanı sıra bu çalışmanın önemli bir diğer üstünlüğü de yukarıda da belirtildiği gibi oldukça geniş bir veri setine dayanmasıdır. Çalışmada Türkiye'nin pamuk yetiştirilen 19 ilinin 1991-2018 yıllarını ait kütlü pamuk üretim miktarı ve fiyatı verileri kullanılmıştır.

\section{Materyal ve Yöntem}

\subsection{Türkiye'de pamuk üretimi, verimliliği ve fiyatları}

Şekil 1'de 1991-2018 yıllarında Türkiye'de pamuk ekili alanların seyri verilmiştir. Şekilden de görüldüğü üzere 1990’lı yılların başlarında pamuk ekili alan 6 milyon dekar düzeyindedir. 1995 yılında önemli bir artış yaşanmış olup bu alan 7.57 milyon dekara çıkmıştır. Fakat sonraki yıllar için genel olarak bir azalma eğiliminin olduğu söylenebilir. Bu azalma eğilimi 2009 yılına kadar devam etmiş olup ekili alanları 4.20 milyon dekar düzeyine kadar azaltmıştır. Türkiye'nin pamuk ekili alanları bu yıldan sonra ise dalgalanmalar göstermekle birlikte daha yatay bir eğilim sergilemiştir. 2018 yılına ait değer 5.19 milyon dekar olmuştur. Bu alan 1991 yılı değeri ile karşılaştırıldığında ekili alanların yaklaşık olarak \%13 azaldığı ortaya çıkmaktadır. 


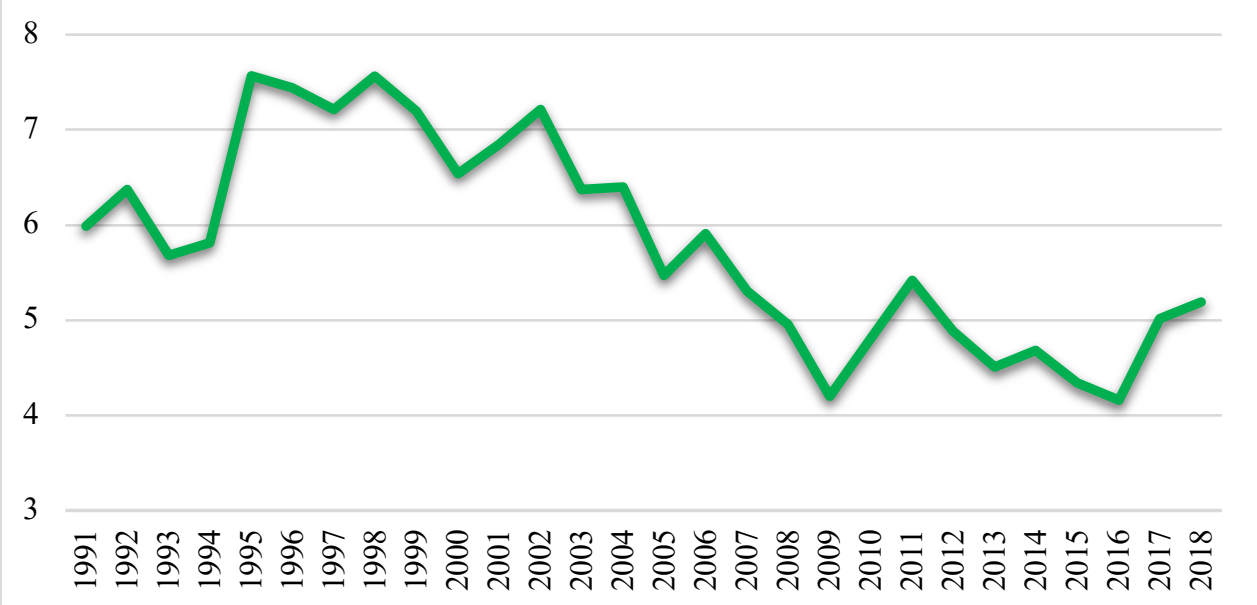

Figure 1. Cotton cultivated area (million decares)

Şekil 1. Pamuk ekili alan (milyon dekar) (TÜİ , 2019a)

Türkiye'de pamuk üretiminin 1991-2018 yıllarına ait seyri ise Şekil 2'de verilmiştir. Görüldüğü üzere Şekil l'de ifade edilen ekili alanların aksine üretim miktarları belirtilen dönemde genel olarak pozitif eğime sahiptir. Bu durum öncelikli olarak ekili alan birimi başına üretim cinsinden verimliliğin de belirtilen dönemde bir artış eğilimine sahip olacağını göstermektedir. Şekil 2'den görüldüğü üzere 1991 yılında Türkiye'de kütlü ve lif pamuk üretim miktarları sırasıyla 1.51 ve 0.56 milyon ton düzeyindedir. 2006 yılına kadar daha belirgin bir artış eğiliminin olduğu söylenebilir. $\mathrm{Bu}$ yılda kütlü ve lif pamuk üretim miktarları sırasıyla 2.55 ve 0.98 milyon ton olmuştur. 2007-2009 yıllarında ise üretimde önemli düşüşle yaşanmıştır. Şekil 1'den görüldüğü üzere aynı yıllarda pamuk ekili alanlarda da keskin azalmalar yaşanmıştır. 2010 yılı ile birlikte üretim miktarının toparlandığı görülmektedir. 2018 yılında ise pamuk üretim miktarları kütlü ve lif pamuk için sırasıyla 2.57 ve 0.98 milyon ton olmuştur. 1991 y1lı değerleri ile karşılaştırıldığında bu üretim miktarları kütlü ve lif pamuk üretiminin sırasıyla \% $\% 0$ ve \%75 oranında arttığına işaret etmektedir.

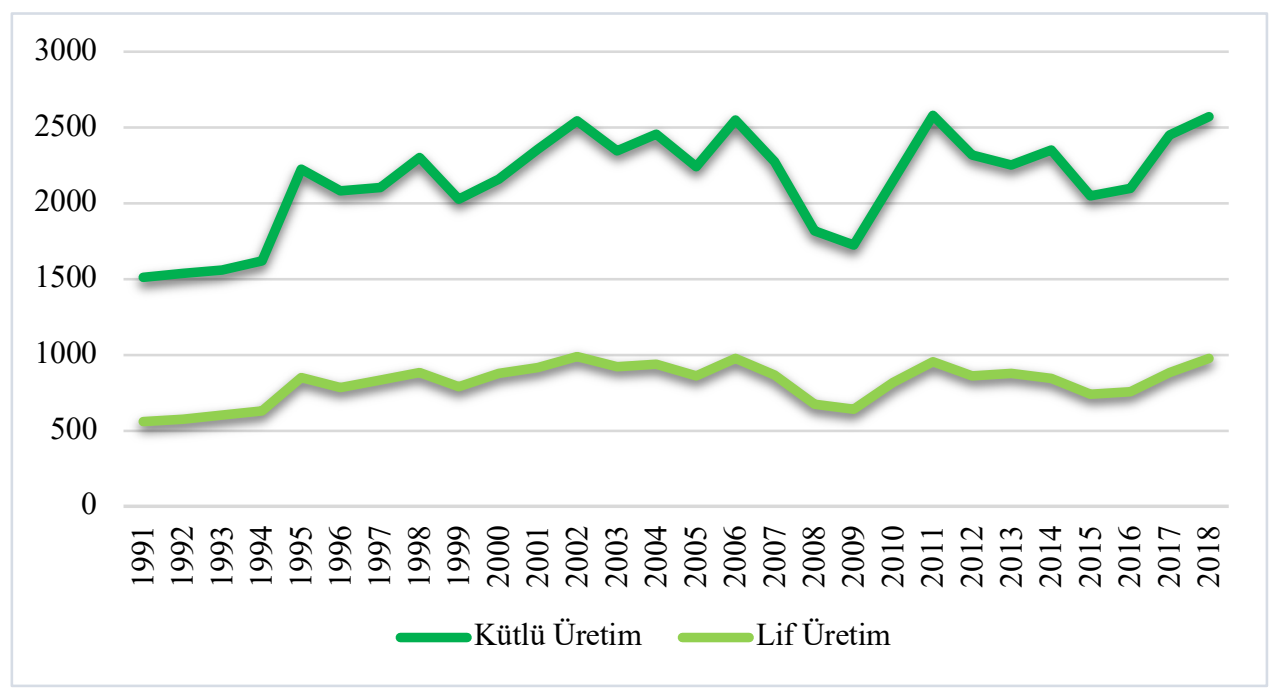

Figure 2. Cotton production (thousand tons)

Şekil 2. Pamuk üretimi (bin ton) (TÜİK, 2019a)

Pamuk üretiminin illere göre dağılımına bakıldığında özellikle Şanlıurfa, Aydın, Hatay, Diyarbakır, Adana ve İzmir'in ön plana çıktığı görülmektedir. Tablo l'de de sunulan 2018 kütlü pamuk üretimi verilerine göre Şanlıurfa yaklaşık olarak 1.03 milyon ton ile Türkiye genelindeki üretimin yaklaşık olarak \%39.99'unu gerçekleştirmektedir. Belirtilen altı ilin aynı yıla ait toplam üretimi ise Türkiye genelindeki üretimin \%84.73'üne karşılık gelmektedir. 
Tablo 1. Illlere göre pamuk üretim miktarı, ekili alan ve verim (2018)

Table 1. Cotton production amount, cultivated area and yield by provinces (2018)

\begin{tabular}{lccc}
\hline & Üretim miktarı (ton) & Ekili alan (dekar) & Verim (kg/dekar) \\
\hline Adana & 206143 & 362543 & 569 \\
Adıyaman & 40635 & 80061 & 508 \\
Antalya & 24832 & 49754 & 499 \\
Aydın & 279377 & 536891 & 520 \\
Balıkesir & 851 & 1911 & 445 \\
Batman & 2982 & 5298 & 563 \\
Denizli & 42517 & 84442 & 504 \\
Diyarbakır & 244497 & 480368 & 509 \\
Gaziantep & 38525 & 74280 & 519 \\
Hatay & 263901 & 485394 & 544 \\
Iğdır & 4275 & 9727 & 439 \\
Kahramanmaraş & 44931 & 85068 & 528 \\
Kilis & 2073 & 4608 & 450 \\
Manisa & 61192 & 102634 & 596 \\
Mardin & 56916 & 107819 & 528 \\
Mersin & 31117 & 52216 & 596 \\
Muğla & 2860 & 6035 & 474 \\
Osmaniye & 2209 & 4442 & 497 \\
Siirt & 1003 & 2133 & 470 \\
Çanakkale & 17 & 47 & 362 \\
İzmir & 156077 & 277434 & 563 \\
Şanlıurfa & 1027625 & 2314303 & 444 \\
Şırnak & 35445 & 58934 & 601 \\
\hline
\end{tabular}

Kaynak: (TÜİK, 2019a)

Şekil 1 ve Şekil 2'de sunulan verilerden hareketle elde edilebilecek olan pamuk için ekili alan verimliliğinin seyri ise Şekil 3’te sunulmuştur. Görüldügüü üzere hem kütlü hem de lif pamukta dekar başına düşen üretim miktarı 19912018 yıllarında pozitif eğime sahip olmuştur. 1999 ve 2008 yıllarında belirgin düşüşlere rağmen arazi verimliliğindeki artışın bir süreklilik gösterdiği söylenebilir. Grafikten görüldüğü üzere 1991 yılında kütlü ve lif pamuk için verimlilik dekar başına sırasıyla 253 ve 93 kilogram iken 2018 yılında 496 ve 188 kilogram olmuştur. Bu rakamlar kütlü ve lif pamuk verimliliğinde $\% 96$ ve \%102 oranında artışa karşılık gelmektedir

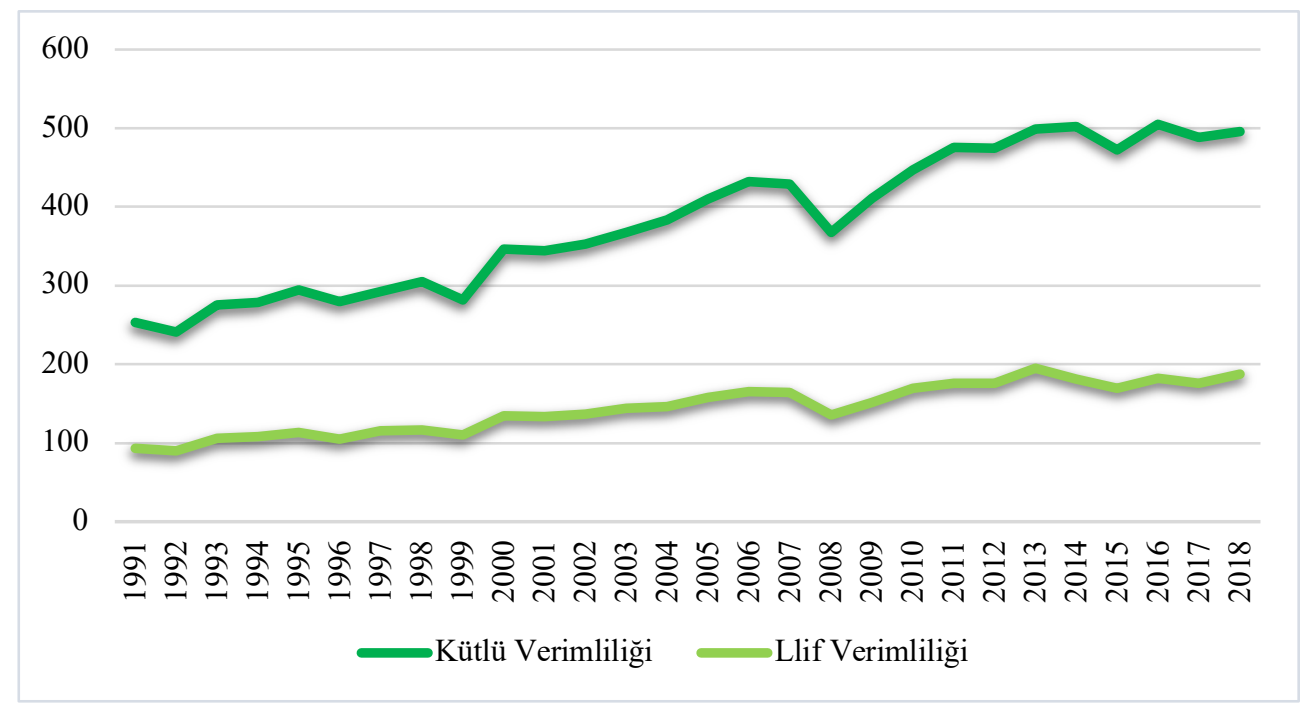

Figure 3. Cotton productivity (kilograms per decare)

Şekil 3. Pamuk verimliliği (dekar başına kilogram) (TÜIK, 2019a) 
Şekil 4'te Türkiye geneli için pamuk kilogram fiyatları verilmiştir. Burada reel fiyatın elde edilmesi için TÜFE $(2010=100)$ değerlerinden yararlanılmıştır. Grafikte görüldüğü üzere Türkiye'de kilogram başına pamuk çiftçinin elde ettiği meblağ 2004 yılına kadar nominal olarak artmıştır. Fakat 2004-2009 yıllarında nominal pamuk fiyatı yatay bir seyre sahiptir. 2010 ve 2011 yıllarında ise önemli fiyat artışlıları yaşanmıştır. 2018 yılına ilişkin pamuk fiyatı ise 2.38 lira olmuştur. Şekilde ifade edilen pamuk reel fiyat serisinin seyrine bakıldığında ise 2009 öncesi yıllarda genel olarak negatif bir eğimin olduğu görülmektedir. Bu durum Türkiye'de pamuk üreticisi için, kilogram başına elde ettiği parasal miktarın TÜFE cinsinden ölçülen hayat pahalılığı karşısında değerinin azaldığını göstermek gibi dezavantajlı bir durumu ifade etmektedir. 2009 ve 2010 yıllarında nominal fiyatta olduğu gibi reel fiyatta da önemli artışlar olmuştur. Fakat 2011 yılındaki düşüşten sonra reel fiyat düzeyi yatay bir seyir göstermiştir. Bu durum belirtilen yıllarda nominal pamuk fiyatındaki artışların yaklaşı olarak TÜFE enflasyonu düzeyinde olduğunu göstermektedir. 1991 ve 2018 yıllarına ait reel fiyatlar karşılaşııııldığında bu fiyatın yaklaşık olarak \%48 oranında azaldığı ortaya çıkmaktadır. Bu durum Şekil 3'te gösterilen dekar başına kilogram cinsinden ölçülen verimlilik değerlerinin aynı dönemde yaklaşık olarak \%100 artması ile birlikte değerlendirildiğinde çiftçinin dekar başına elde ettiği reel gelirde pek bir değişikliğin olmadığı anlaşılmaktadır.

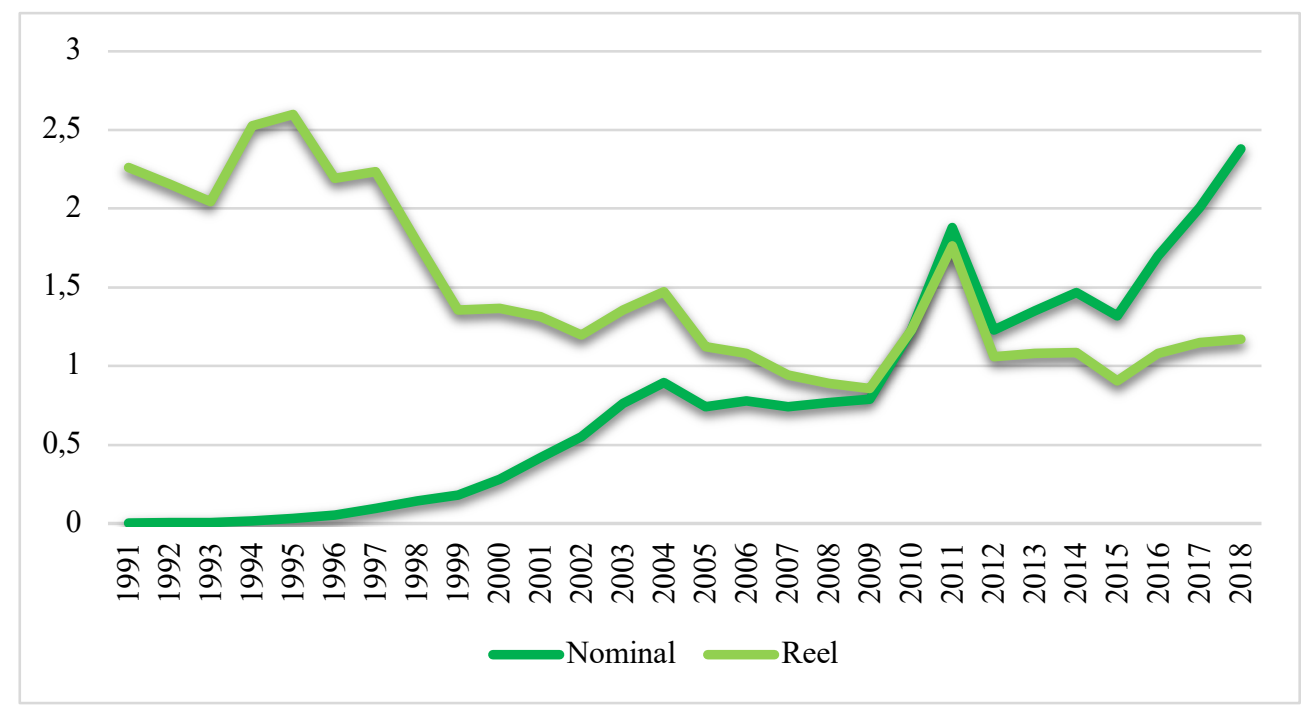

Figure 4. Cotton prices

Şekil 4. Pamuk fiyatları (TÜIK, 2019b)

\subsection{Ekonometrik Yöntem}

\subsubsection{Koyck yaklaşımı}

Tarım ürünlerinin üretiminde üreticilerin miktara ilişkin kararları ürünün cari dönem fiyatının yanı sıra daha önceki dönemlerdeki fiyatlarından da önemli derecede etkilenebilmektedir. Cari dönem fiyatı da gelecek dönemlerde yetiştirilmesi planlanan ürün miktarına ilişkin kararlarda etkili olmaktadır. Bu şekilde ürüne ait cari dönem fiyatın yanı sıra geçmiş dönem fiyatların, başka bir ifade ile fiyatların gecikmeli değerlerinin de üretim miktarı üzerinde etkili olduğu durumlarda üretim miktarlarına ilişkin yapılan tahminlerde gecikmesi dağıtılmış modeller yaygın şekilde kullanılmaktadır. Bu çalışmada Türkiye'de pamuk üretim miktarına ilişkin yapılan tahminler de gecikmesi dağıtılmış modellerden olan Koyck yaklaşımı çerçevesinde yapılmıştır. Bu yaklaşım aşağıda ifade edilen tek açıklayıcı değişkenli gecikmesi sonsuz dağıtılmış modelden hareketle açıklanabilir (Gujarati ve Porter, 2012) :

$$
y_{t}=\alpha+\beta_{0} x_{t}+\beta_{1} x_{t-1}+\beta_{2} x_{t-3}+\cdots+u_{t}
$$

Eşitlikte görüldüğü gibi $y_{t}$ değişkeni $x_{t}$ değişkeni ve sonsuz sayıdaki gecikmesi ile açıklanmaktadır. Koyck(1954) 1 numaralı eşitlikle gösterilebilen gecikmesi sonsuz dağıtılmış modelde yer alan bütün $\beta$ 
katsayılarının aynı işaretli olduğunu ve bu katsayıların geometrik bir şekilde eşitlik 2'de ifade edildiği gibi azaldığını varsaymıştır:

$$
\beta_{k}=\beta_{0} \lambda^{k} \quad k=0,1, \ldots
$$

Burada $\lambda$ gecikmeli değişkenlere ait katsayıların azalma oranı olup $0<\lambda<1$ 'dir. $1-\lambda$ ise uyarlama hızını ifade etmektedir. $\lambda$ katsayısının 1'den küçük olması her sonraki gecikmeye ait $\beta$ katsayısının öncekinden düşük olmasına neden olmaktadır. Koyck modelinde ortalama gecikme süresi ise $\lambda /(1-\lambda)$ şeklinde hesaplanmaktadır.

Koyck (1954), önce gecikmesi sonsuz dağıtılmış modelde $\beta$ katsayılarına ilişkin yukarıdaki dönüşümü gerçekleştirmiştir. Bu durumda 1 numaralı eşitlikle gösterilen model aşağıdaki şekilde (Eş.3) ifade edilebilir:

$$
y_{t}=\alpha+\beta_{0} \lambda^{0} x_{t}+\beta_{0} \lambda^{1} x_{t-1}+\beta_{0} \lambda^{2} x_{t-2} \ldots+u_{t}
$$

Ardından bu modelin bir dönem gecikmeli değerleri için oluşturmuş formunu $\lambda$ ile çarparak ikinci bir denklem (Eş.4) oluşturur:

$$
\lambda y_{t-1}=\lambda \alpha+\beta_{0} \lambda^{1} x_{t-1}+\beta_{0} \lambda^{2} x_{t-2}+\beta_{0} \lambda^{3} x_{t-3} \ldots+\lambda u_{t-1}
$$

Son olarak 3 ve 4 numaralı eşitliklerin farkını kullanarak Koyck modeli olarak bilinen aşağıdaki modele ulaşır (Eş.5):

$$
y_{t}=\alpha(1-\lambda)+\beta_{0} x_{t}+\lambda y_{t-1}+v_{t}
$$

Görüldüğü üzere 5 numaralı eşitlikte açıklayıcı değişken olarak 1 numaralı eşitlikle ifade edilen gecikmesi sonsuz dağıtılmış modeldeki bağımsız değişkenin kendisi yani $x_{t}$ ve bağımlı değişkenin bir dönem gecikmesi yani $y_{t-1}$ yer almaktadır.

\subsubsection{Panel veri sabit etkiler modeli}

Bu çalışmada Türkiye'de pamuk üretim miktarı için yapılan tahmin panel veri seti kullanılarak yapılmıştır. Panel veri model seçim testleri sonucunda sabit etkiler modelinin kullanılmasına karar verilmiştir. Türkiye'de pamuk üretim miktarı ve fiyatlarına ait 1991 yılı öncesi verilerine ilişkin erişim sorunları veya bu verinin mevcut olmamasından dolayı sınırlı gözlem sayısı dikkate alındı̆̆ında zaman serisi yöntemlerine nispeten panel veri yöntemlerinin önemli avantajları ortaya çıkmaktadır. Pamuk yetiştirilen birçok ile ait üretim ve aynı zamanda illere göre farklılaşan fiyatlara ilişkin verilerin mevcut olması panel veri yöntemlerinin kullanılmasına olanak sağlamaktadır. Bilindiği gibi panel veri daha çok gözlem sayısına imkân verdiğinden dolayı daha çok bilgi içermesi, daha değişken olması, açıklayıcı değişkenler arasında çoklu doğrusalığın daha az olması, serbestlik derecesinin daha yüksek olması ve tahminlerin daha etkin ve güvenilir olması gibi birçok avantaja sahiptir. Bunun yanı sira panel veri setine dayanan tahminlerde birimlerin ya da yatay kesitlerin birbirinden farklı olmaları yani türdeş olmamalar modellenebilmektedir.

Yukarıda da ifade edildiği gibi bu çalışmada panel veri sabit etkiler yöntemi kullanılmıştır. Panel veride farklı birimler veya yatay kesitler mevcut olduğundan dolayı her birime ilişkin gözlemlenemeyen etkiler olabilir. Panel veri tesadüfi etkiler modelinde bu gözlemlenemeyen etkilerin hata terimi gibi tesadüfi bir değişken olduğu varsayılır. Bu durumda modele ilişkin sabit terimin büyük bir ana kitleden tesadüfi olarak çekildiği düşünülür. Sabit etkiler modelinde ise gözlemlenemeyen etkilere her bir birime ilişkin bir katsayı ile modellenmektedir. Bu nedenle sabit etkiler modeli kukla değişkenli en küçük kareler modeli olarak da bilinmektedir. İlave olarak tesadüfi etkiler modelinde birim etkiler ile açıklayıcı değişkenlerin korelasyonsuz, sabit etkiler modelinde ise korelasyonlu olduğu varsayılır. Tek açıklayıcı değişken için sabit etkiler modeli aşağıdaki eşitlik 6 ile ifade edilebilir:

$$
y_{i t}=\alpha_{i}+\beta x_{i t}+u_{i t}
$$


Burada $i$ paneldeki birimleri, $t$ ise dönemleri göstermektedir. Her bir birime ait sabit terim birbirinden farklı olabileceği için $\alpha$ parametresinin indisinde de $i$ yer almaktadır. Yukarıda ifade edilen model, birimlere ilişkin $i-$ 1 sayıda kukla değişkenle tahmin edildiğinden her bir birime özgü farklı sabit terime ulaşılabilmektedir.

\subsubsection{Birimler arası korelasyon ve durağanlık testleri}

Model tahminine geçmeden önce çalışmada verilerin durağanlık özelliklerinin incelenmesi gerekmektedir. Çünkü panel veride de durağan olmayan serilerle yapılan tahminler yanıltıcı sonuçların ortaya çıkmasına neden olabilir. Panel birim kök testleri ise yatay kesitlerin korelasyonlu olup olmadığına ilişkin farklı varsayımlar içermektedir. Bu nedenle çalışmada pamuk üretim miktarı ve pamuk fiyatı değişkenleri için birimler arası korelasyon Pesaran (2004) CD testi uygulanarak incelenmiş ve test sonuçları doğrultusunda birimler arası korelasyonun varlığı dikkate alınarak uygun birim kök testi kullanılmıştır. Pesaran (2004) dengesiz paneller için $\sqrt{\frac{2}{N(N-1)}} \sum_{i=1}^{N-1} \sum_{j=i+1}^{N} \sqrt{T_{i j}} \hat{\rho}_{i j}$ istatistiğini önermiştir. Burada $\hat{\rho}_{i j}$ korelasyon katsayılarını, $N$ yatay kesit sayısını ve $T_{i j}$ ise korelasyon katsayısı hesaplanan gözlem sayısını göstermektedir.

Birimler arası korelasyon test edildikten sonra çalışmada pamuk üretim miktarı ve reel pamuk fiyatları değişkenlerinin durağanlık özellikleri yatay kesit bağımlılı̆̆ını dikkate alan Pesaran (2007) panel birim kök testi kullanılarak incelenmiştir. Yatay kesit ADF (CADF) olarak bilinen bu teste ait temel modeller ADF (Genişletilmiş Dickey ve Fuller, 1981) birim kök testine ait modellere dayanmaktadır. Pesaran (2007) CADF testi temel modelinde birimler arası korelasyon yatay kesit ortalamaların gecikmeli değerleri ile modellenmektedir. Hata terimlerinde, yatay kesit ortalaması gecikmeli değerine ve birinci farkına ilişkin faktör yapısında otokorelasyon sorununu gidermek amacıyla modele bağımlı değişkenin ve yatay kesit ortalamalarının farkının gecikmeleri eklenir. CADF temel modeli aşağıdaki eşitlik 7 ile ifade edilebilir (Pesaran, 2007):

$$
\Delta y_{i t}=a_{i}+b_{i} y_{i, t-1}+c_{i} \bar{y}_{t-1}+\sum_{j=0}^{p} d_{i j} \Delta \bar{y}_{t-j}+\sum_{j=1}^{p} \delta_{i j} \Delta y_{i, t-j}+e_{i t}
$$

Burada $\bar{y}_{t}$ tüm $N$ sayıdaki gözlemin ortalamasıdır. Durağanlık testinin sonuçları panelde yer alan her bir yatay kesit için belirlenen $b$ katsayısına ilişkin hesaplanan $t$ istatistiğine göre değerlendirilebilmektedir. CIPS istatistiki ise bu $t$ istatistiklerin ortalaması şeklinde $\left(\frac{1}{N} \sum_{i=1}^{N} C A D F_{i}\right)$ hesaplanmaktadır. Teste ait hipotezler ise $H_{0}: b_{i}=0$ ve $H_{1}: b_{i}<0 i=1,2, \ldots, N_{1} ; b_{i}=0 i=N_{1}+1, N_{1}+2, \ldots, N$ şeklinde ifade edilebilir. Burada sifir hipotezi paneldeki her bir birime ait verinin birim kök içerdiği ve alternatif hipotez ise en az bir panel birimi için verinin birim kök içermediğini ifade etmektedir. Teste ait kritik değerler ise Pesaran (2007) çalışmasında bulunmaktadır (Ağazade, 2016).

\subsubsection{Panel veri tahmin yönteminin seçimi}

Durağanlık incelemesinin ardından Koyck yaklaşımı çerçevesinde Türkiye'de pamuk üretim miktarı için oluşturulan model için panel veri sabit etkiler ve tesadüfi etkiler yöntemlerinden hangisinin uygun olduğunu belirlemek amacıyla Hausman (1978) testi uygulanmıştır. Daha önce de ifade edildiği gibi tesadüfi ve sabit etkiler modelleri arasında birim etkiler ile açıklayıcı değişkenlerin korelasyonlu olup olmamasına ilişkin fark bulunmaktadır. Hausman (1978) testi de bu korelasyonun incelenmesine dayanmaktadır. Test istatistiği $H=$ $\left(\hat{\theta}_{f}-\hat{\theta}_{r}\right)^{\prime}\left[C\left(\hat{\theta}_{f}\right)-C\left(\hat{\theta}_{r}\right)\right]^{-1} \hat{\theta}_{f}-\hat{\theta}_{r}$ şeklinde ifade edilmektedir. Burada $\hat{\beta}_{f}$ ve $\hat{\beta}_{r}$ sirasılya sabit etkiler ve tesadüfi etkiler modellerine ait katsayılardır. $C\left(\hat{\beta}_{f}\right)$ ve $\mathrm{C}\left(\hat{\beta}_{r}\right)$ ise ilgili modellerden elde edilen asimptotik varyans kovaryans matrisleridir (Greene, 2016). Hausman (1978) testine ait sifir hipotezi modelin hata terimleri ile açıklayıcı değişkenlerinin korelasyonsuz, alternatif hipotez ise korelasyonlu olduğunu ifade etmektedir. Bu durumda sıfır hipotezinin geçerli olması durumunda tesadüfi etkili, alternatif hipotezin geçerli olması durumunda ise sabit etkili model sonuçları geçerli olacaktır.

\subsubsection{Sabit etkili modele ilișkin temel varsayımların incelenmesi}

Hausman (1978) testi sonuçları doğrultusunda Türkiye'de pamuk üretim miktarı için Koyck yaklaşımı çerçevesinde oluşturulan model sabit etkiler yöntemine göre tahmin edilmiştir. Bu model için birimler arası değişen varyans sorunu değiştirilmiş Wald, otokorelasyon sorunu Bhargava ve ark.'in (1982) Durbin-Watson (DW, Baltagi ve Wu'nun (1999) yerel en iyi değişmezlik (LBI) testleri ile incelenmiştir. Birimler arası korelasyonun incelenmesi ise daha önce de bahsedildiği gibi Pesaran (2004) CD testine dayanmaktadır. 

Değiştirilmiş Wald test istatistiği $W=\sum_{i=1}^{N} \frac{\left(\hat{\sigma}_{i}^{2}-\sigma^{2}\right)^{2}}{\operatorname{Var}_{i}}$ şeklinde hesaplanmakta olup teste ait temel hipotez hata terimlerinin varyansının panel birimlerine göre sabit olduğunu ifade eder. Küçük standart sapmalara ve etkinlik sorununa neden olan otokorelasyon incelemesi için hesaplanan DW ve LBI test istatistiklerinin ise 2'den küçük olması durumu pozitif otokorelasyon sorununun varlığına işaret eder (Baltagi, 2013; Tatoğlu, 2012).

Koyck yaklaşımı çerçevesinde pamuk üretim miktarı modelinin sabit etkiler yöntemine göre yapılan tahmini için birimlere göre değişen varyans ve birimler arası korelasyon sorunlarının olduğu görülmüştür. Bu nedenle çalışmada belirtilen sabit etkiler modeli değişen varyans, otokorelasyon ve yatay kesit bağımlılı̆̆ı problemlerinin varlığında dirençli tahminciler veren Driscoll ve Kraay'ın (1998) yaklaşımı kullanılmıştır. Driscoll ve Kraay (1998), metodolojisi yatay kesit ortalamaları serisi için Newey-West türü düzeltme yaparak kovaryans matris tahmincilerinin tutarlılı̆̆ını garantilemektedir (Tatoğlu, 2012).

\subsection{Veri Seti}

Türkiye'de pamuk üretim miktarı ile pamuk fiyatları arasındaki ilişkinin incelendiği bu çalışmada panel veri seti kullanılmıştır. Veri seti, pamuk yetiştirilen 19 ile ait ton cinsinden yıllık kütlü pamuk üretim miktarları, kütlü pamuğun aynı illere ait kilogram fiyatları ve bu fiyatların reel dönüşümlerini sağlamak amacıyla kullanılan Türkiye geneline ait TÜFE $(2010=100)$ değerlerinden oluşmaktadır. Çalışma kapsamındaki iller Adana, Adıyaman, Antalya, Aydın, Balıkesir, Batman, Denizli, Diyarbakır, Gaziantep, Hatay, Kahramanmaraş, Manisa, Mardin, Mersin, Muğla, Siirt, İzmir, Şanlıurfa ve Şırnak’tır. Araştırma dönemi 1991-2018 yıllarını kapsamaktadır. İllerde yetiştirilen pamuk üretim miktarlarının ve fiyatlarının bazı yıllara ait verileri bulunmadığından çalışmada yapılan tahminler dengesiz panel veriye dayanmaktadır. Pamuk üretim miktarı ve fiyatına ait veriler TÜIKK Bitkisel Üretim İstatistikleri ile Tarımsal Fiyat ve Ekonomik Hesaplar veri tabanlarından alınmıştır (TUIK, 2019 b,c).

Yukarıda da ifade edildiği gibi bu çalışmada, hayat pahalılı̆ıının bir göstergesi olarak TÜFE kullanılarak pamuk fiyatlarının reel dönüşümleri yapılmış ve pamuk üretimi için miktar ve fiyat ilişkisi analizinde reel pamuk fiyatlar kullanılmıştır. Burada amaç, özellikle yüksek ve değişken enflasyonun yaşandığı dönemlerde, fiyatlar genel düzeyindeki değişmeleri hesaba katmadan belirli bir ürünün fiyatında ortaya çıkan değişimlerin, bu ürünü arz ve talep edenlerin kararlarında etkili olacak derecede önemli bir bilgiyi ifade etmemesi gibi bir sorunun üstesinden gelmektir. Bu çalışmada, 1991-2018 olmak üzere 29 yıllık bir döneme ait veri kullanılmıştır. 1990’lı yıllarda Türkiye'de enflasyon oranları hayli yüksek olmuştur. 2000'li yıllarda ise bu oranın tek haneli rakamlara indiği gözlemlenmiştir. Fiyatlar genel düzeyindeki veya hayat pahalılı̆ı̆ındaki artışın bu şekilde değişken olduğu bir dönemde belirli bir ürün için üretim miktarı ve fiyat ilişkisi incelenirken analizlerde nominal fiyatların kullanılması yanıltıcı veya pek de bir bilgi ifade etmeyen sonuçların elde edilmesine neden olabilir. Çünkü malların üretim veya talep miktarına ilişkin verilen kararlar, nominal fiyatlardan çok nispi yani malların diğer mallar cinsinden fiyatlarına ya da reel fiyatlarına göre verilebilmektedir. Bu nedenle, çalışmada pamuk için enflasyondan arındırılmış ya da reel dönüşümü yapılmış fiyat serisi oluşturulmuş ve üretim miktarı ve fiyat ilişkisine yönelik analizlerde bu seri kullanılmıștır. Reel fiyatları elde etmek için TÜFE $(2010=100)$ değerlerinden yararlanılmış olup bu seri (nominal fiyat $* 100 / T U ̈ F E$ ) şeklinde hesaplanmıştır. Böylelikle 2010 y1lı pahalılık düzeyi ile hesaplanan pamuk fiyat serisi elde edilmiştir.

\section{Araştırma Sonuçları ve Tartışma}

\subsection{Birimler arası korelasyon ve birim kök testlerine ait sonuçlar}

Çalışmada ton cinsinden pamuk üretim miktarı kilogramla ifade edilerek analizlerde logaritmik değerleri kullanılmıştır. Ayrıca illere ait kütlü pamuk kilogram fiyatları ile TÜFE değerleri kullanılarak pamuk için reel fiyat değişkeni oluşturulmuştur.

Pamuk üretim miktarı logaritmik serisi $(L Q)$ ve reel pamuk fiyatları serisi $(R P)$ için panel birimleri arasında yatay kesit bağımlılığının incelendiği Pesaran (2004) CD testi ve ikinci nesil panel birim kök testlerinden Pesaran (2007) CADF testi bulguları Tablo 2'de verilmiştir. Tabloda da ifade edildiği gibi her iki değişken için CD test istatistikleri panel birimlerinin korelasyonsuz olduğunu ifade eden sıfir hipotezini $\% 1$ anlamlılık düzeyinde reddetmektedir. Tabloda aynı zamanda her iki değişken için birimler arası ortalama korelasyon katsayısı da verilmiştir. Buna göre $L Q$ değişkeni için araştırmaya dahil edilen iller arasında \%21.6 ve $R P$ değişkeni için \%90.4 pozitif korelasyon mevcuttur. CD testi sonucuna dayanarak çalışmada uygulanan Pesaran (2007) CADF ikinci 
nesil birim kök testine ait Tablo 2'de ifade edilen istatistikler de anlamlı bulunmuştur. $L Q$ değişkeni için CADF istatistiği paneldeki her bir birime ait verinin birim kök içerdiğini ifade eden sıfir hipotezini $\% 5, R P$ değişkeni için ise $\% 1$ düzeyinde reddetmektedir. Bu sonuçlara dayanarak Koyck yaklaşımı çerçevesinde pamuk üretimi için yapılan tahminlerde değişkenlerin seviye değerleri kullanılmıştır.

Tablo 2. Birimler arası korelasyon ve panel birim kök testine ait sonuçlar

Table 2. Cross-sectional correlation and panel unit root test results

\begin{tabular}{|c|c|c|c|}
\hline & CD & Korelasyon & CADF \\
\hline$L Q$ & $14.8389^{*}$ & 0.216 & $-1.939 * *$ \\
\hline$R P$ & $60.1011 *$ & 0.904 & $-9.532 *$ \\
\hline
\end{tabular}

Not: * ve ** simgeleri ilgili istatistiğin sırasıyla \%1 ve \%5 düzeyinde almalı olduğunu gösterir.

\subsection{Türkiye'de pamuk için Koyck yaklaşımı panel veri tahmin sonuçları}

Türkiye'de pamuk üretimi için Koyck modeli çerçevesinde oluşturulan model aşağıdaki Eşitlik 8 ile ifade edilebilir:

$L Q_{i t}=\alpha+\beta L P_{i t}+\gamma L Q_{i t-1}+v_{i t}$

Bu model için Hausman (1978) testi $\chi^{2}$ istatistiği 54.9978 olarak bulunmuştur. Bu istatistik modelin hata terimlerinin ve açıklayıcı değişkenlerinin korelasyonlu olmadığını ve dolayısıyla tesadüfi etkiler modelinin geçerli olduğunu ifade eden sıfir hipotezini \%1 anlamlılık düzeyinde reddetmektedir. Bu sonuca dayanarak yukarıda ifade edilen model sabit etkiler yöntemine göre tahmin edilmiştir.

Fakat bu tahmin sonuçlarına geçmeden önce modelde panel birimlerine göre değişen varyans, otokorelasyon ve birimler arası korelasyon sorunları incelenmiştir. Değişen varyans için değiştirilmiş Wald test istatistiği \%1 düzeyinde istatistiksel olarak anlamlı ve 1049.10 bulunmuştur. Bu bulgu modelde birimlere göre değiş̧en varyans sorununun varlı̆̆ına işaret etmektedir. Otokorelasyon sorununun incelenmesi için hesaplanan DW ve LBI istatistiklerinin sırasıyla 1.8684 ve 2.0720 olduğu görülmüştür. Bu istatistiklerin 2'ye yakın değerde olması ciddi otokorelasyon sorununun olmadığına işaret etmektedir. Birimler arası korelasyonu test etmek için hesaplanan Pesaran (2004) CD istatistiği ise 15.218 ve \%1 düzeyinde istatistiksel olarak anlamlı çıkmıştır. Dolayısıyla CD istatistiği model için yatay kesit bağımlılığının varlığına işaret etmektedir. Pamuk üretim miktarı için sabit etkiler modeli temel varsayımlarına ilişkin test sonuçları birimlere göre değişen varyans ve birimler arası korelasyona işaret ettiğinden sabit etkiler modeline ilişkin tahminde Driscoll ve Kraay (1998) dirençli standart hataları dikkate alınmıştır.

Türkiye'de pamuk üretimi için Koyck yaklaşımı çerçevesinde sabit etkili modelin tahmin sonuçları Tablo 3 'te sunulmuştur. Yapılan tahmin veride bazı gözlemlerin bulunmaması ve bağımlı değişken gecikmesinin neden olduğu veri kaybından dolayı 488 gözleme dayanmaktadır. Tablodan da görüldüğü üzere $R P$ değişkenine ait katsayı pozitiftir. Bu katsayının değeri 0.2074 ve $t$ istatistiği \%1 düzeyinde anlamlıdır. Bağımlı değişkenin bir dönem gecikmesi yani $L Q(-1)$ değişkeni için bulunan katsayı değeri ise 0.8330 'dur. Bu katsayı için $t$ istatistiği de $\% 1$ düzeyinde anlamlıdır. Modele ait $F$ istatistiği anlamlı ve $\mathrm{R}^{2}$ değeri yaklaşık olarak \%94 düzeyinde olmuştur. $R P$ ve $L Q(-1)$ değişkenlerine ait tahmin edilen katsayılar şu şekilde değerlendirilebilir. Pamuk reel fiyatlarında 1 liralık bir değişme pamuk üretim miktarını aynı yönde yaklaşık olarak \%20.74 oranında etkilemektedir. Reel pamuk fiyatına ilişkin ortalama değerin 1.5177 olması dikkate alındığında bu durum, pamuk reel fiyatında \%1 oranındaki bir değişimin pamuk üretiminde aynı yönde \%0.32'lik bir değişime neden olduğu şeklinde de ifade edilebilir. Pamuk üretim miktarında önceki yıl ortaya çıkan \%1'lik değişme cari yıldaki miktarı aynı yönde ve yaklaşık olarak $\% 0.83$ oranında etkilenmektedir.

Türkiye'de pamuk üretim miktarı için panel veriye göre Koyck yaklaşımı çerçevesinde yapılan ve Tablo 3'te verilen tahminin ardından Pamuk üretim miktarı için gecikmesi dağııılmış modelin tahminine geçilmiștir. Burada $L Q$ değişkeni $R P$ ve gecikmelerinin bir fonksiyonu olarak tahmin edilmiştir. Sabit etkilere göre tahmin edilen bu modelde optimal gecikme uzunluğu Schwarz bilgi kriterine göre 2 olarak belirlenmiştir. Gecikmesi dağı̆tılmış modele ilişkin tahmin sonuçları ise Tablo 4'te verilmiştir. 
Türkiye’de Pamuk Üretimi İle Fiyatı Arasındaki İlişkinin Koyck Yaklaşımı İle Analizi

Tablo 3. Türkiye'de pamuk üretimi için Koyck yaklaşımı tahmin sonuçları

Table 3. Koyck approach estimation results for cotton production in Turkey

\begin{tabular}{ccccc} 
& Katsayı & $\begin{array}{c}\text { Drisc/Kraay } \\
\text { Std. S. }\end{array}$ & t istatistiği & p değeri \\
\hline$R P$ & 0.2074 & 0.0553 & 3.75 & 0.001 \\
$L Q(-1)$ & 0.8330 & 0.0472 & 17.65 & 0.000 \\
Sabit & 2.6527 & 0.8653 & 3.07 & 0.007 \\
\hline
\end{tabular}

Tablo 4. Türkiye’de pamuk üretimi için gecikmesi dağıtılmış model tahmin sonuçları

Table 4. Estimation results of distributed lag model for cotton production in Turkey

\begin{tabular}{ccccc}
\hline & Katsayı & $\begin{array}{c}\text { Drisc/Kraay } \\
\text { Std. S. }\end{array}$ & t istatistiği & p değeri \\
\hline$R P$ & 0.1188 & 0.1251 & 0.95 & 0.355 \\
$R P(-1)$ & 0.1679 & 0.0727 & 2.31 & 0.033 \\
$R P(-2)$ & 0.1670 & 0.1075 & 1.55 & 0.138 \\
Sabit & 17.0830 & 0.2412 & 70.82 & 0.000 \\
\hline
\end{tabular}

Tablodan da görüldüğü üzere tahmin edilen modelde RP değişkeni ve tüm gecikmelerine ait katsayılar pozitiftir. Modelde yer alan açıklayıcı değişkenlerden $R P(-1)$ 'e ait katsayılar \%5 düzeyinde istatistiksel olarak anlamlı bulunmuştur. Modele ait $\mathrm{R}^{2}$ değeri Koyck modeli ile karşılaştırıldığında daha düşük ve yaklaşık olarak \%81 olduğu görülmüştür. Daha önce de ifade edildiği gibi gecikmesi dağıtılmış modelin tahmini önemli miktarda gözlem kaybına neden olmaktadır. Sonuçları Tablo 4'te sunulan gecikmesi dağıtılmış model 430 gözleme dayanmaktadır. Bunun yanı sıra RP değişkenine ait gecikmelerin modelde yer alması çoklu bağlantı sorunlarına neden olabilir. Bu nedenle pamuk üretim miktarının cari ve geçmiş yıllara ait reel fiyatlara göre tahmininin Tablo 3'te ifade edilen Koyck yaklaşımı katsayılarının kullanılması ile 2 numaralı eşitlik yardımıyla yapılması önemli avantajlar sağlamaktadır. Bu durumda cari yıl ve 2 yıl gecikmeli reel fiyatlara ilişkin katsayılar aşağıdaki gibi olur:

$$
\begin{aligned}
& \beta_{0}=\lambda^{0} \beta_{0}=0.8330^{0} * 0.2074=0.2074 \\
& \beta_{1}=\lambda^{1} \beta_{0}=0.8330^{1} * 0.2074=0.1728 \\
& \beta_{2}=\lambda^{2} \beta_{0}=0.8330^{2} * 0.2074=0,1439
\end{aligned}
$$

Bu durumda Türkiye'de pamuk üretim miktarı için Koyck yaklaşımına dayanan gecikmesi dağıtılmış model de aşağıdaki eşitlik 9 şekilde yazılabilir:

$$
L Q_{i t}=2.6527+0.2074 R P_{i t}+0.1728 R P_{i t-1}+0.1439 R P_{i t-2}
$$

Buna göre reel pamuk fiyatında yani meydana gelen 1 liralık bir değişme pamuk üretimini aynı yıl \%20.74 oranında ve aynı yönde etkilemektedir. Reel pamuk fiyatındaki bu değişme 1 ve 2 yıl sonraki üretimi ise sırasıyla \%17.28 ve \%14.39 oranında etkilemektedir. Pamuk reel fiyatına ait ortalama değer dikkate alındığında cari y1l, 1 ve 2 yıl öncesine ait fiyattaki \%1'lik değişimin etkisi ise sırasıyla \%0.31, \%0.26 ve \%22 olarak hesaplanmaktadır. $\lambda /(1-\lambda)$ şeklinde hesaplanan reel fiyat değişmelerinin üretim miktarına yansımasını ifade eden ortalama gecikme süresi ise 4.99 yıl olarak bulunmaktadır.

\section{Sonuç}

Bu çalışmada pamuk üretim miktarı ile reel pamuk fiyatları arasındaki ilişki Türkiye’nin 19 ilinin 1991-2018 yıllarına ait veriler kullanılarak incelenmiştir. Çalışmada öncelikle araştırma döneminde üretim miktarı, ekili alan, verim ve fiyat serilerinin seyirleri incelenmiştir. Pamuk reel fiyatları ve ekili alan göstergelerinin seyri reel fiyatlarda 1990'lı yılların ikinci yarısında önemli düşüşlerin olduğunu ve ekili alanların da fiyat düşüşlerini takiben 2000'li yıllarla birlikte azaldığını göstermektedir. Fakat verim artışından dolayı, ekili alanlardaki azalma bu dönemde üretim miktarına yansımamıştır.

Çalışmanın amacı doğrultusunda ise öncelikle Pesaran (2004) CD testi kullanılarak pamuk üretim miktarı ve reel pamuk fiyatları serileri için panel birimleri (iller) arasında yatay kesit bağımlılı̆̆ı incelenmiştir. Bu teste ait bulgular her iki değişken için yatay kesit bağımlılığına işaret etmekte ve farklı illere ait üretim değerlerinin ve reel fiyat 
değişkenlerinin korelasyonlu olduğunu göstermektedir. Yatay kesit bağımlılığın incelenmesinin ardından çalışmada birimler arası bağımlılığı modelleyen Pesaran (2007) panel birim kök testi aracılı̆̆ ile değişkenlerin durağanlık özellikleri incelenmiştir. Bu test ait bulgular her iki değişkenin seviyesinde durağan olduğunu desteklemiştir. Bu durum üretim miktarı veya reel pamuk fiyatını etkileyen dışsal şokların etkilerinin geçici olduğunu, serilerin uzun dönem düzeylerine dönme eğilimi gösterdiğini ifade etmektedir. Durağanlık incelemesinin ardından panel veri model seçim testleri uygulanarak Türkiye için pamuk üretim miktarı için oluşturulan model Koyck yaklaşımı çerçevesinde panel veri sabit etkili modele göre tahmin edilmiştir. Koyck yaklaşımı çerçevesinde elde edilen sonuçlar pamuk üretim miktarının reel fiyat esnekliğinin düşük ve fiyat değişmelerinin üretim miktarına yansıması için geçmesi gereken ortalama sürenin uzun olduğunu göstermiştir. Şöyle ki reel pamuk fiyatlarında ortaya çıkan \%1'lik bir değişme cari yıl üretimini yaklaşık olarak \%0.31 oranında aynı yönde etkilemektedir. Reel pamuk fiyatlarında 1 ve 2 yıl önce ortaya çıkan $\% 1$ 'lik değişmeler ise üretim miktarını sırasıyla $\% 0.26$ ve $\% 0.22$ oranında ve fiyat değişimleri ile aynı yönde etkilemektedir. Fiyatlarda ortaya çıkan değişmelerin üretim miktarına yansıması için gereken ortalama sürenin ise 4.99 yıl olduğu bulunmuştur.

Elde edilen sonuçlar, pamuk üretiminin fiyat esnekliğinin düşük olduğuna ve üretim miktarının fiyat değişikliklerine uyum gösterme sürecinin ise önemli derecede uzun olduğuna işaret etmektedir. Özellikle girdi maliyetlerinde artışların ve arz koşullarının geliştirilmesini engelleyen kısıtların neden olabileceği bu durum dikkate alındığında üretim miktarının artırımasına yönelik fiyat merkezli yaklaşımların önemli bir başarı sağlamayacağı düşünülmektedir. Bunun yanı sıra, tarım sektörünün genelinde karşılaşıldığı gibi pamuk üretiminde de istihdamın, özellikle genç istihdamının düşük sosyal statü ile ilişkilendirilmesinin de fiyat ve üretim miktarı ilişkisinin zayıf kalmasında etkili olduğu düşünülmektedir. 
Ağazade, S. (2016). Doğu Avrupa geçiş ekonomilerinde rekabet ve gelir düzeyi ilişkisi. Rekabet Dergisi 66: 120 -146.

Akgül, S., Yıldız, Ş. (2016). Yozgat'ta buğday üretimi ve fiyat ilişkisinin Koyck modeliyle analizi. Bozok Üniversitesi Uluslararası Bozok Sempozyumu. 5-7 Mayıs, Yozgat. 178-188.

Aktaş, E. (2006). Çukurova Bölgesi’nde pamuk arz duyarlılığının tahmini üzerine bir çalışma. Tarım Ekonomisi Dergisi 12 (1): 3-8.

Arısoy, H., Bayramoğlu, Z. (2017). Determination of the effect of price fluctuation on producer income the case of potatoes. Turkish Journal of Agriculture -Food Science and Technology 5 (11): 1342-1349.

Baltagi, B.H. (2013). Econometric analysis of panel data. 5th ed., John Wiley and Sons Ltd., UK.

Baltagi, B.H., Wu, P.X. (1999). Unequally spaced panel data regressions with AR(1) disturbances. Econometric Theory 15 (6): $814-823$.

Berk, A. (2017). The analysis of relationship sunflower production and its price by using Koyck model in Turkey. Custos e@gronegocio on line 13 (4): $42-53$

Bhargava, A., Franzini, L., Narendranathan, W. (1982). Serial correlation and the fixed effects model. The Review of Economic Studies 49 (4): 533-549.

Çelik, Ş. (2014). Türkiye'nin kabuklu fındık üretiminde üretim-fiyat ilişkisinin Koyck yaklaşımı ile analizi. Türk Tarım ve Doğa Bilimleri Dergisi 1 (4): 524-530.

Çelik, Ş. (2015). Koyck ve Almon gecikme modeli ile koyun sütü üretiminde üretim- fiyat ilişkisinin analizi: Türkiye örneği. Akademik Bakış Dergisi 50: 137-149.

Çetinkaya, Ş. (2012). Türkiye'nin son on yıllık buğday üretimindeki miktar-fiyat ilişkisinin ekonometrik analizi: Koyck-Almon tekniği. İnsan ve Toplum Bilimleri Araştırmaları Dergisi 4 (1): 52-66.

Dickey, D.A., Fuller, W.A. (1981). Likelihood ratio statistics for autoregressive time series with a unit root. Econometrica 49 (4): $1057-1072$.

Dikmen, N. (2006). Koyck-Almon yaklaşımı ile tütün üretimi ve fiyat ilişkisi. Çukurova Üniversitesi Sosyal Bilimler Enstitüsü Dergisi 15 (2): $153-168$

Doğan, H.G., Gürler, A.Z., Ayyıldız, B. (2014). Patates üretiminde üretim-fiyat ilişkisinin Koyck yaklaşımı ile analitik olarak değerlendirilmesi (TR71 bölgesi örneği). Türk Tarım-Gıda Bilim ve Teknoloji Dergisi 2 (1): 42-46.

Driscoll, J.C., Kraay, A.C. (1998). Consistent covariance matrix estimation with spatially dependent panel data. The Review of Economics and Statistics 80 (4): 549-560.

Erdal, G. (2006). Tarımsal ürünlerde üretim-fiyat ilişkisinin Koyck yaklaşımı ile analizi (domates örneği). Gaziosmanpaşa Üniversitesi Ziraat Fakültesi Dergisi 23 (2): 17-24.

Erdal, G., Erdal, H. (2008). Kuru soğanda üretim fiyat etkileşimi. Gaziosmanpaşa Üniversitesi Ziraat Fakültesi Dergisi 25 (1): $33-39$.

Eski, Ö., Kayalak, S. (2018). Türkiye'de pamuk üretimi için bir öngörü modeli Var yaklaşımı. Çanakkale Onsekiz Mart Üniversitesi Ziraat Fakültesi Dergisi 6: 131-137.

Greene, W.H. (2016). Ekonometrik çözümleme. Yedinci baskıdan çeviri, Palme Yayıncılık, Ankara.

Gujarati, D.N., Porter, D.C. (2012). Temel ekonometri. Beşinci baskıdan çeviri, Literatür Yayınları, İstanbul.

Hausman, J. (1978). Specification tests in econometrics. Econometrica 46 (6): 1251-1271.

Karaman, S., Koçak, A., Tezel, G. (2015). Determinants of cotton prices in Turkey: A Var approach. Tarım Ekonomisi Araştırmaları Dergisi $1(2): 1-8$.

Koyck, L.M. (1954). Distributed lags and investment analysis. North-Holland Publishing, Amsterdam.

Önder, K. (2017). Pamuk arzını etkileyen faktörlerin panel veri ile analizi. Eskişehir Osmangazi Üniversitesi İIBF Dergisi 12 (1): $83-98$.

Özbay, N., Çelik, Ş. (2016). Türkiye'de üretim-fiyat ilişkisinin almon gecikme modeli ile incelenmesi. Kahramanmaraş Sütçü İmam Üniversitesi Doğa Bilimleri Dergisi 19 (2): 141-146.

Özçelik, A., Özer, O.O. (2006). Koyck modeliyle Türkiye’de buğday üretimi ve fiyat ilişkisinin analizi. Tarım Bilimleri Dergisi 12 (4): 333 339.

Özer, O., İlkdoğan, U. (2013). Box-Jenkins modeli yardımıyla dünya pamuk fiyatının tahmini. Tekirdağ Ziraat Fakültesi Dergisi 10 (2): 1320.

Özer, O.O., Özçelik, A., Kayalak, S. (2014). Geçmiş fiyatlar ile fark ödeme sisteminin pamuk üretimine etkisi. XI. Ulusal Tarım Ekonomisi Kongresi 3-5 Eylül, Samsun, 830-835.

Özüdoğru, T., Miran, B. (2015). Türkiye'de farklı destekleme politikalarının pamuk arzı üzerine etkileri. Tarım Ekonomisi Araştırmaları Dergisi 1 (2): 9-19. 
Pesaran, M.H. (2004). General diagnostic tests for cross section dependence in panels. Cambridge Working Papers in Economics 0435.

Pesaran, M.H. (2007). A simple panel unit root test in the presence of cross-section dependence. Journal of Applied Econometrics 22 (2): 265312.

Semerci, A., Çelik, A.D. (2018). Hatay ilinde pamuk üretiminin fonksiyonel analizi. Tekirdăg Ziraat Fakültesi Dergisi 15 (2): $78-86$.

Tatoğlu, F.Y. (2012). Panel veri ekonometrisi. Beta Basım, İstanbul.

TÜİK. (2019a). Bitkisel Üretim İstatistikleri, https://data.tuik.gov.tr/Kategori/GetKategori?p=tarim-111\&dil=1, (Erişim tarihi: 13.11.2019).

TÜIKK. (2019b). Tarımsal Fiyat ve Ekonomik Hesaplar, https://data.tuik.gov.tr/Kategori/GetKategori?p=tarim-111\&dil=1, (Erişim tarihi: 13.11.2019)

TÜİK. (2019c). Tüketici Fiyat Endeksi, (TÜFE) https://data.tuik.gov.tr/Kategori/GetKategori?p=enflasyon-ve-fiyat-106\&dil=1, (Erişim tarihi: 13.11.2019).

Yurdakul, F. (1998). Pamuk üretimi ile pamuk fiyatları arasındaki ilişkinin ekonometrik analizi: Koyck ve Almon yaklaşımı. Çukurova Üniversiteis IIBF Dergisi 8 (1): 343-351. 